\title{
Fundamental regulations concerning novel food products and food for special medical purposes with plant ingredients
}

\author{
JUSTYNA BARANIAK*, MAŁGORZATA KANIA-DOBROWOLSKA
}

\author{
Department of Pharmacology and Phytochemistry \\ Institute of Natural Fibres and Medicinal Plants \\ Kolejowa 2, \\ 62-630 Plewiska, Poland \\ *corresponding author: phone: +48 6166595 50, fax: +48 6165171 92, e-mail: justyna.baraniak@iwnirz.pl
}

\section{Summary}

\begin{abstract}
A lot of products from food category specified in Regulation No. 609/2013 may contain herbal substances or their preparations. Definitions of food for infants and toddlers, food for special medical purposes, and total diet replacement for weight control are now clearly regulated by UE food legislation. The concept and definition of foodstuffs for particular nutritional published in Directive 2009/39/EC of the European Parliament and Council of 6 May 2009 do not apply. On 22 February 2019, Commission Delegated Regulation (EU) 2016/128 complementary to Regulation (EU) No. 609/2013, regarding specific compositional and information requirements for food of special medical purposes was applied. Novel foods and novel food ingredients are foods which have not been used for human consumption in UE to a significant degree before 15 May 1997.
\end{abstract}

Key words: herbal substances, Union food law, food for special medical purposes, novel food

Słowa kluczowe: surowce roślinne, prawo żywnościowe UE, żywność specjalnego przeznaczenia medycznego, nowa żywność

\section{INTRODUCTION}

Food products are subjected to food law and European legislation. A lot of food products contain different herbal substances. They are popular in all
European countries. Plants contain biological substances of beneficial effect on human health. That is why ingredients of different products often belong to the category of food. Among food for specific nutritional purposes, dietary supplements or functional 
products as well as particular parts of plants (leaves, flowers, fruit, seed, roots) or their preparations (juices, extracts) can be taken into consideration. However, all these food products, especially dietary supplements, contain mostly vitamins and mineral compounds as well as natural enzymes, amino acids, fatty acids, fiber, probiotics and products from bee honey [1]. First of all, vitamin preparations are prepared as tablets or capsules, in many products in powdered or liquid form. In food supplements minerals, oils obtained from fish and plant material can be found, as defined in the food supplement definition [1]. In addition, functional foods are widely known in EU countries as a new group of products. Functional food is enriched or enhanced by substances with known health benefits. The composition is adapted to specific nutritional requirements of particular consumer. The specific nutritional component of particular product must be biologically useful for the human body and is regarded as a potential substance with high health benefit.

\section{Types of food defined in Regulation (EU) No. $609 / 2013$}

By this time, foodstuffs for particular nutritional uses belong to the category of food and are regulated by European Union regulations and directives as well as by Polish law. Dietetic food was defined as prepared to fulfill special dietary needs of particular persons. Currently, Regulation (EU) No. 609/2013 of the European Parliament and of the Council of 12 June 2013 on food intended for infants and young children, food for special medical purposes, and total diet replacement for weight control is obligatory. Consequently, Council Directive 92/52/EEC, Commission Directives 96/8/EC, 1999/21/EC, 2006/125/EC and 2006/141/EC, Directive 2009/39/EC of the European Parliament and of the Council and Commission Regulations (EC) No. 41/2009 and (EC) No. 953/2009 have been repealed [2]. From 20 July 2016, these new rules must be applied in formulation of products. What is important, the definition of foodstuffs for particular nutritional uses has been deleted from food legal acts. This Regulation gives the guidelines on composition and information concerning types of food strictly defined in the European Union - infant formula and followon formula, processed cereal-based food and baby food, food for special medical purposes and total diet replacement for weight control. The composition of food mentioned in Regulation 609/2013 is created to satisfy specific dietary needs of particular groups. It takes into account the latest scientific literature data in this matter. Additionally, Regulation No. 609/2013 establishes an Union list of vitamins, minerals, amino acids, carnitine, taurine, nucleotides, choline and inositol that may be added to food mentioned above [2]. Union list of this substances is determined and placed as Annex added to Regulation (EU) No. 609/2013.

\section{Food for special medical purposes (FSMPs)}

The definition of food for special medical purposes according to abovementioned regulations says that it is food specially prepared for the special nutrition of patients and infants. This kind of food must be used under medical supervision. It is dedicated to patients with impaired absorption of food, abnormal absorption and metabolization of food and incorrect excretion of certain nutrients or metabolites, or with other medically-determined nutrient requirements, whose dietary management cannot be achieved by modification of normal diet alone [2]. From 22 February 2019, Commission Delegated Regulation (EU) 2016/128 complementary to Regulation (EU) No. 609/2013 applies. According to Regulation (EU) 2016/128 of 25 September 2015, food formulations for special medical purposes are prepared in cooperation with the health service to feed patients with nutritional problems as a result of their disease, disorder or other medical recommendations. For that reason, food for special medical purposes is recommended for use under medical supervision, which should be administered or accepted with help of other competent health professionals [3]. FSMPs are addressed to people who due to particular medical condition or health problems have nutritional needs that cannot be met by normal food. Food for special medical purposes is assigned directly to patients to whom food other than FSMPs is inadequate. It is very important to know that this kind of food must be used only under medical supervision and also be properly marked with a label describing their particular composition and use (it means that modification of normal diet is not enough for them). Food for special medical purposes belongs to the food group of a wide variety. Moreover, development potential of science and need to ensure the adequate flexibility to develop innovative products makes it impossible to create detailed compositional rules for these products. However, basic guidelines relating to the content of vitamins 
and minerals in food for special medical purposes as well as the rules concerning nutritional composition of food for special medical purposes developed to satisfy the nutritional requirements of infants must be established [3].

The EFSA Panel on Dietetic Products, Nutrition and Allergies (NDA) had prepared scientific and technical guidance for the assessment of products considered as food for special medical purposes in accordance with Article 3 of Regulation (EU) No. $609 / 2013$. This document contains guidance helpful in the preparation of well-structured dossiers for food products considered as foods for special medical purposes on the market. The dossier of particular product must comprise all information concerning food product proposed as food for special medical purposes, the disease or the medical condition, profile of patients or the medical condition for which the food product is intended and used, any restrictions and - most important - specific role of the food product proposed as foods for special medical purposes in the dietary management of patients with disease or medical condition for which food product is intended [4]. In the context of guidance mentioned above, disease is caused by characteristic set of symptoms which are helpful in proper diagnosis. Medical condition denotes specific alteration, management of which requires nutritional intervention under medical supervision. Food product is suitable for human consumption. In EFSA guidance, we cannot find information about foods named "gluten-free" and "lactose-free", meal replacements for weight control and other categories of food falling under Regulation (EU) No. 609/2013.

It is particularly important that in case of food for special medical purposes nutrition and health claims (also for plants or plant parts present in this products) cannot be applied [3].

\section{Novel food and safety}

Another important category of food widely launched on the market is "novel food". Novel foods and novel food ingredients have not been used for human consumption to a significant degree before the entry into force of the Regulation (15 May 1997) [1]. Novel foods are, for example, traditional foods eaten elsewhere in the world or foods produced using completely new processes or extracts from exotic plants or their parts never eaten before. Novel food may be marketed in European Union under key conditions. Each product must undergo a safety assessment and authorisation under the Novel Foods Regulation (EU) No. 2015/2283 [5]. The regulation applies to any food and food ingredient that had not been used in the EU for human consumption to a significant degree before May 1997, including food ingredients with a new or modified molecular structure (for example new sources of vitamins), micro-organisms as well as algae and fungi, cell cultures, food produced in new production process that significantly changes this particular product (for example UV-treated milk or bread), engineered nano-materials or well unknown plants or their extracts not used before as food or which has been traditionally eaten outside of the EU, also animals. It should be mentioned that food additives, flavourings and extraction solvents used in the production process of food products are subject to separate legislation.

Authorised novel foods must exist under a few conditions. First of all must be safe, properly and clearly labelled for the consumer, not replace other foods in a way that misleads the consumer about nutritional properties. Novel food status of each new/unknown ingredient can be checked in the European Union Novel food catalogue [6], German novel food list, Italian list of plants permissible or not permissible for food supplement use or different guidance on history of consumption. European Union published Union list of authorised novel foods [7]. On EU websites we can also find all refusals of authorisation of novel foods and novel food ingredients by Commission Decisions. In Regulation (EU) 2017/2470 we can find authorised novel food and also conditions under which the novel food may be used. The plant ingredients that are included here are for example: Ajuga reptans extract from cell cultures, algal oil from the microalgae Ulkenia sp., Aloe macroclada Baker leaf extracts, argan oil from Argania spinosa, fermented black bean extracts, magnolia bark extract, noni leaves (Morinda citrifolia), fermented soybean extract, Cistus incanus L. Pandalis herb, coriander seed oil from Coriandrum sativum, dried extract of Lippia citriodora from cell cultures and much more [8]. The Annex to Implementing Regulation (EU) 2017/2470 was replaced by the Annex to Commission Implementing Regulation (EU) 2018/1023 of 23 July 2018 correcting Implementing Regulation (EU) 2017/2470 establishing the Union list of novel foods [9].

The European Commission is updating the EU list and and completes it with newly authorised novel foods. Updates from 2019 to the Union list of novel foods are for example as follow: Commission Implementing Regulation (EU) 2019/109 of 
24 January 2019 authorising an extension of use of Schizochytrium sp. oil as a novel food under Regulation (EU) 2015/2283 of the European Parliament and of the Council, and amending Commission Implementing Regulation (EU) 2017/2470 or Commission Implementing Regulation (EU) 2019/110 of 24 January 2019 authorising an extension of use of Allanblackia seed oil as a novel food under Regulation (EU) 2015/2283 of the European Parliament and of the Council and amending Commission Implementing Regulation (EU) 2017/2470 [10, 11]. European Commission published also summary of applications and notifications based on the informations sent by applicant [7].

Additionally, the e-submission system was created to meet the requirements of the applicant who wants to submit novel foods applications and/or traditional foods notifications from third countries online. User guide was published by European Commission and the system is very helpful for the user. EFSA published also very helpful guidance documents in the EFSA Journal, for example guidance on the preparation and presentation of an application for novel food, administrative guidance of novel foods and guidance on the preparation and presentation of the notification and application for authorisation of traditional foods from third countries.

A lot of criteria are considered when establishing whether food has been used for 'human consumption to a significant degree'. According to information placed in document 'Human Consumption to a Significant Degree', in case of plant material the following information must be provided a lot of important information. First of all - taxonomic name of the organism with full Latin name, author's name, other known names or synonyms and specification of the use of part of the organism earlier than on 15 May 1997 refers to, the form and/or concentration of the product. Additionally, in case of food supplement possible indication of the quantity or amount of particular ingredients (also herbal substances) must be declared.

\section{CONCLUSIONS}

The definition of food supplements, food for special medical purposes or novel food - categories of food containing, among others, herbs are clearly defined. Use of all these products varies in separate European Union countries, but increasing intake (also containing herbal substances or their preparations) by different groups of consumers is still observed.
Definitely, detailed European Union regulations concerning all of these product categories, their constituents (particularly herbal substances) and also their safety are required. It is important to create a harmonized list of plant raw materials which can be placed in food products in all European Union countries. The improvement of the quality of these products is also extremely important. Finally, scientific safety data and results of examinations submitted by the applicant company to a Member State competent authority concerning food product, as well as safety assessment performed by European Food Safety Authority (EFSA) is crucial for health safety of potential consumer in future.

Ethical approval: The conducted research is not related to either human or animal use.

Conflict of interest: Authors declare no conflict of interest.

\section{REFERENCES}

1. Baraniak J, Kujawski R, Ożarowski M. Law regulations concerning food supplements and novel food containing herbal substances. Herba Polonica 2016; 62(4):97-106. doi: http://dx.doi. org/10.151/hepo-2016-0025

2. Regulation (EU) No. $609 / 2013$ of the European Parliament and of the Council of 12 June 2013 on food intended for infants and young children, food for special medical purposes, and total diet replacement for weight control and repealing Council Directive 92/52/EEC, Commission Directives 96/8/EC, 1999/21/EC, 2006/125/EC and 2006/141/EC, Directive 2009/39/EC of the European Parliament and of the Council and Commission Regulations (EC) No. 41/2009 and (EC) No. 953/2009. Official Journal of the European Union. L 181/35-56.

3. Commission Delegated Regulation (EU) 2016/128 of 25 September 2015 supplementing Regulation (EU) No. 609/2013 of the European Parliament and of the Council as regards the specific compositional and information requirements for food for special medical purposes.

4. EFSA. Scientific and technical guidance on foods for special medical purposes in the context of Article 3 of Regulation (EU) No. 609/2013. EFSA 
Journal 2015; 13(11):4300.

5. Regulation (EU) 2015/2283 of the European Parliament and of the Council of 25 November 2015 on novel foods, amending Regulation (EU) No. 1169/2011 of the European Parliament and of the Council and repealing Regulation (EC) No. 258/97 of the European Parliament and of the Council and Commission Regulation (EC) No. $1852 / 2001$. Official Journal of the European Union. L 327/1-22.

6. http://ec.europa.eu/food/safety/novel_food/catalogue

7. https://ec.europa.eu/food/safety/novel_food/authorisations-and-notifications_en

8. Commission Implementing Regulation (EU) 2017/2470 of 20 December 2017 establishing the Union list of novel foods in accordance with Regulation (EU) 2015/2283 of the European Parlia- ment and of the Council on novel foods.

9. Commission Implementing Regulation (EU) 2018/1023 of 23 July 2018 correcting Implementing Regulation (EU) 2017/2470 establishing the Union list of novel foods.

10. Commission Implementing Regulation (EU) 2019/109 of 24 January 2019 authorising an extension of use of Schizochytrium sp. oil as a novel food under Regulation (EU) 2015/2283 of the European Parliament and of the Council, and amending Commission Implementing Regulation (EU) 2017/2470.

11. Commission Implementing Regulation (EU) 2019/110 of 24 January 2019 authorising an extension of use of Allanblackia seed oil as a novel food under Regulation (EU) 2015/2283 of the European Parliament and of the Council and amending Commission Implementing Regulation (EU) 2017/2470. 